\title{
Del Expresionismo a la Revolución: fundamentos estéticos y políticos de la Räterepublik (1918-1919)
}

\section{From Expressionism to Revolution: Aesthetic and Political Foundations of the Räterepublik (1918-1919)}

\author{
Ana Rodríguez \\ Universitat Oberta de Catalunya. Cataluña, España. \\ arodriguezgrane@uoc.edu
}

\section{Resumen}

Este artículo pretende exponer los vínculos que se establecieron entre las ideas estéticas surgidas durante el Romanticismo alemán y el discurso político de la Revolución Bávara en el noviembre de 1918. A través de un recorrido por el proceso de politización del movimiento expresionista, veremos cómo conceptos filosóficos, provenientes del misticismo romántico y de la filosofía nietzscheana, se incorporaron en el pensamiento político filoanarquista de la Räterepublik con la intención de, paradójicamente, superar estratos utópicos y llevar a la praxis su proyecto social alternativo de izquierdas. De este modo, intentaremos insertar los discursos de Kurt Eisner, Erich Müsahm o Gustav Landauer en el debate sobre la refundación de lazos comunitarios como parte de la dialéctica moderna y la crítica a la razón ilustrada.

Palabras clave: Revolución de Noviembre, misticismo, irracionalismo, marxismo heterodoxo, Romanticismo alemán

\section{Abstract}

This article aims to expose the links between the aesthetic ideas of German Romanticism and the political discourse of the Bavarian Revolution of November 1918. By examining the process of politicization of the expressionist movement, we will see how concepts originated from Nietzschean philosophy or romantic mysticism were incorporated into the philoanarchist thought of the Räterepublik, in order to paradoxically overcome utopian strata and bring to praxis their alternative left wing social project. Thus, we will try to insert the discourses of Kurt Eisner, Erich Müsahm or Gustav Landauer in the debate on the modern dialectic and the critic to enlightened reason.

Keywords: November Revolution, Mysticism, Irrationalism, heterodox Marxism, German Romanticism 


\section{Introducción}

Desde los estudios sobre historia de la cultura del periodo de entreguerras, encontramos una multitud de análisis sobre la constitución de alternativas políticas a ciertas ideas liberales y modernas. El auge del fascismo y el nacionalsocialismo fueron la cristalización de ese otro proyecto moderno revolucionario. ${ }^{1}$ Tras la Segunda Revolución Industrial alemana, a partir de 1885, movimientos como el vegetarianismo y el esoterismo, el nudismo o el panteísmo, entre otras utopías comunitarias antiburguesas, evidencian problemáticas con la modernidad que serán heredadas en el debate intelectual de la República de Weimar. ${ }^{2}$ Sin embargo, la crítica romántica al positivismo, extendida durante el siglo $\mathrm{xx}$, no solo es parte fundamental del misticismo conservador sino que también de movimientos asociados a la izquierda más allá de la socialdemocracia y el comunismo. La Rätereplublik que siguió a la Revolución de Noviembre -entre noviembre 1918 y abril 1919- puede ser entendida como un movimiento político enmarcado en esa dialéctica moderna: entre la necesidad de la razón y la incorporación de los impulsos irracionales como parte fundamental del individuo, la Revolución de Noviembre constituye un marco interesante para analizar cómo, desde ese magma de crítica al positivismo, el campo artístico y político tomaron la herencia idealista para la refundación de los lazos comunitarios. La esperanza en la posibilidad de un nuevo orden social y la vuelta sobre el misticismo abonó tanto el pensamiento conservador como la heterodoxia marxista siguiendo la senda del romanticismo anticapitalista. ${ }^{3}$

En esta investigación propongo visibilizar el proceso de politización de algunas figuras ligadas al expresionismo alemán durante la Revolución de Noviembre, como Kurt Eisner, Erich Müsahm y Gustav Landauer, y los fundamentos políticos y estéticos que nutrieron parte de ese breve pero intenso capítulo de la historia alemana. De este modo, analizaremos los vínculos teóricos de la fracasada Räterepublik con la tradición idealista y romántica; su inspiración en la filosofía nietzscheana y la construcción del discurso sobre el rol del arte en un contexto revolucionario. A través del papel distintivo del irracionalismo en el contexto alemán, intentaremos exponer cómo el arte y el misticismo se convirtieron en elementos de crítica y rechazo a otras posturas panteístas, revolucionarias y autoritarias que siguieron en auge después de la Primera Guerra Mundial. Lejos de pretender realizar un ensayo apologista del

1 Algunos de estos estudios son los de Roger Griffin o Jeffrey Herf, siguiendo la propuesta conceptual del teórico de la Nueva Derecha Arnin Mohler en los años cincuenta (Die Konservative Revolution in Deutschland 1918-1932), han partido de la idea de un modernismo reaccionario asociado a esa cultura antiliberal gestada desde el siglo xIX en lo que viene a ser parte de una nueva historiografía que toma en consideración de forma preponderante la historia cultural dialogando con la historia política y social como sucede en las obras de Emilio Gentile, George Mosse o Zern Sternhell.

2 Véase por ejemplo Mosse (“The Mystical”, La cultura europea). Sobre el debate en torno la Modernidad existe el compendio de Phelan.

3 Tal como lo expresa Michael Löwy, ya en Marx y Engels existe un interés por los historiadores de primitivas comunidades rurales y por los primeros románticos como prefiguración de la pérdida de valores sociales en la civilización industrializada en Löwy. 
romanticismo marxista, vamos a intentar comprender las mixturas y subsiguientes contradicciones que emergieron en el cambio de siglo entre dos posiciones comúnmente consideradas estancas: la del misticismo y la necesidad de la razón. Nuestra intención es, a la postre, arrojar algo de luz sobre la forma en que ciertas alternativas al marxismo ortodoxo intentaron resolver las contradicciones modernas entre el sujeto emancipado y el excesos racionalistas. Además, ahondar en estas cuestiones pretende visibilizar un periodo muy poco estudiado en los documentos de la historia del arte y que, sin embargo, propone un prolijo caso para el análisis de los vínculos entre las ideas estéticas y el arte político.

\section{El retorno a la comunidad como alternativa crítica en el Romanticismo alemán}

Ya la primera crítica romántica a la modernidad ilustrada se inscribe en esos términos dialécticos donde, ante la emergencia de un nuevo sujeto social, la cultura habría de asumirse como vector político y como vínculo a la comunidad. En los albores del romanticismo, encontrábamos las primeras acusaciones y divergencias políticas que apuntaron a dos alternativas de modernidad diferenciadas y que pretendían corregir los excesos del racionalismo ilustrado. Ante la pérdida de legitimación del Estado moderno - extensión de los conflictos derivados de la Revolución Francesa y guerras napoleónicas-, tal como anunciara Ernst Bloch en El principio esperanza los años treinta, el Romanticismo alemán, aun conteniendo una mirada hacia el pasado, imaginaba un porvenir utópico. Si se podía mantener un ápice común entre toda la amalgama literaria y artística vinculada al movimiento romántico era la apuesta por un subjetivismo desligado de cualquier ley impuesta: "Estos poetas, en sus primeras obras, acabaron con todas las reglas fabricadas hasta entonces, empezando desde la nada" (Hegel 21-7).

El movimiento ilustrado y la razón como forma de gobierno (Estado) y conocimiento (Ciencia) se iban imponiendo a medida que las cuestiones estéticas asumían también parangón político. En este proceso de la modernidad, el movimiento romántico y la filosofía idealista se encargaron de resituar todos aquellos desechos que quedaban fuera del imperio de la lógica y del empirismo: pasiones, emociones, deseos, impulsos primitivos, capacidad creativa, entre otras. Immanuel Kant en la Crítica del Juicio había discernido ya la función no utilitarista pero sí ética y moral del arte y la cultura como libre juego de las facultades. La consecuente deriva del axioma kantiano fue una politización de la estética como marco político y espacio para la libertad del sujeto. Dicho espacio funcionaba no era concebido como una fuga o escape de las pulsiones reprimidas en sociedad, sino como el principio articulador de la voluntad moral del individuo en el seno social. A fin de cuentas, el movimiento romántico emergía como crítica a la despreocupación de la ciencia y el conocimiento racional frente al conocimiento intuitivo del sujeto. 
De este modo, a través de una política cultural y educativa que consideraba como materia prima los impulsos, deseos y voluntades del alemán, la aspiración a la belleza, la idea de pertenencia, figuras como Johann G. Fichte, Johann G. Herder o Friedrich Schiller contrapusieron la idea de Kultur a las desafecciones de la civilización, ${ }^{4}$ según los románticos, un concepto extranjero impuesto por el invasor francés e instrumento de gobierno externo a los verdaderos deseos del individuo.

Así pues, a partir del discurso político de Novalis La cristiandad o Europa, escrito en 1799 y publicado por Schlegel en 1806, vemos cómo la Europa Medieval se convertía en la alegoría utópica de un anhelado cosmopolitismo pacífico que la secularización provocada por la Revolución Francesa no lograba alcanzar: "un sólo país cristiano, una cristiandad vivía humanamente configurada y un gran interés comunitario unía las más lejanas provincias de este vasto imperio espiritual" (71).

Esta reivindicación ante la noche del mundo - proceso de secularización y rechazo del componente religioso como aglutinador social- permitía pensar otras vías alternativas de modernidad, enalteciendo el sustrato mítico que todavía canalizaba las formas de relación del sujeto con el mundo. Así fue cómo, a finales del xIx, los mitos generados en torno a conceptos como Vida, Alma, Nación, Totalidad o Reich fueron asumidos de forma tan eficiente por la Revolución Conservadora (Bloch, Heritage 3). Incluso la misma idea de revolución, tradicionalmente propiedad de la izquierda, será uno de los mitos apropiados por la derecha radical de los conservadores. ${ }^{5}$

Sin embargo, ya desde principios del xix, las derivas que tenían por objeto la corrección del proyecto moderno ilustrado derivarán hacia posturas encontradas. Desde la Revolución de Julio de 1830 -fecha señalada como muerte del movimiento romántico- aquellas figuras que habían estado ligadas al Círculo de Jena -como las de Heinrich Heine, Georg W. F. Hegel y Friedrich Schlegel- empiezan ya a proferir una serie de giros y escisiones que señalan las dos posturas perpetradas durante los años venideros. De estas dos posturas podemos señalar, a grandes rasgos, una de tendencia irracionalista con tintes regresivos; frente a otra de carácter racional sostenida, en principio, por el ala progresista.

Tras las guerras napoleónicas Schlegel, defensor de la causa restauracionista, encarnó la bandera nacionalista contra la Ilustración francesa recurriendo "al mundo medieval y cristiano 'germano' como el origen cultural y espiritual para resistir y renovarse, es decir, cuando el programa artístico es convertido en una ideología para la política cultural" (Domínguez 52). En La escuela romántica, escrito en defensa de la Junges Deutschland, ${ }^{6}$

4 Tal como se desarrolló profusamente en la obra de Norbert Elias, El proceso de la civilizacion. Investigaciones sociogenéticas y psicogenéticas.

5 En la conferencia de Hugo von Hofmannsthal de 1927, "La palabra escrita como espacio espiritual de la Nación" (157-70) en una vuelta sobre los románticos, alude por primera vez la idea de una Revolución Conservadora. Las bases del concepto también se encuentran de forma desarrollada en la obra de Moeller van den Bruck de 1923 Das Dritte Reich (El Tercer Reich).

6 El movimiento de la Joven Alemania pensada como movimiento de vanguardia de la intelectualidad ilustrada y liberal. 
Heine remetería contra esas desviaciones nacionalistas del romanticismo alemán -al que se refería de forma peyorativa-. Del mismo modo funcionaría la crítica de Hegel al movimiento que sublimó al arte como ideología política y como valor sagrado. Esta concepción que había sido desarrollada por Schelling, y que alimentó la política cultural romántica de credo y patria, constituían un retroceso premoderno para Hegel y Heine (Domínguez 57).

Así, la apelación a lo no racional -los deseos, afectos y emociones- emergían como elementos de autenticidad, como elementos puros de cohesión social en tanto identidad común apriorística o prepolítica que los nacionalistas convirtieron en verdadera voluntad del Volk y contra el instrumentalismo benthamista de fines meramente utilitaristas. Axel Honneth señala que es, precisamente, durante el primer Romanticismo cuando podemos apreciar una mayor preocupación por designar los vínculos que constituyen los distintos modelos sociales, más allá de la arquitectura jurídica o el contrato que los constituye (9). Es a partir de esos momentos que los conceptos de comunidad en oposición a la sociedad empezarán a ser diferenciados sistemáticamente. Comenta Honneth que es durante el postidealismo de Hegel y de Lorenz van Stein cuando esas categorías preracionales -la religión, la cultura común, la etnia o los afectos- se constatarán como verdadero elemento de cohesión social.

La reescritura del pasado seguirá alimentando el imaginario utopista del siglo xx y el factor irracionalista se transformará, con o contra el rito de afirmación nacional, en el reclamo para la creación de un modelo de producción alternativo a las relaciones capitalistas. Desde posturas diversas, surgieron utopías comunitarias tanto de carácter conservador (Rohkrämer 31-42) como progresista: hermandades y gremios feudales, como modelos equitativos de intercambio; propuestas de retorno a lo rural, como la comuna vegetariana de Monte Veritá en Ascona, la Vegetarische Obstbaukolonie Eden (Colonias Vegetarianas Eden) en Berlin; proyectos de planificación urbana; comunidades de producción horizontales y colectivizadas inspiradas en William Morris, ${ }^{7}$ entre otras experiencias. Imbuidos también de las corrientes misticistas, emergieron ideas arquitectónicas, como las de Bruno Taut, lector de la traducción del Maestro Eckahrt de Landauer; en la Glashaus o Casa de Cristal (1914) insertada luego en el proyecto urbanístico de la Stadtkrone (Corona de la Ciudad) de 1916, también inspirada en Incitación al socialismo de Landauer (Cirlot y Vega 199-240); o la misma Sozialistische Bund (Liga Socialista), fundada en 1908 por este último junto a Erich Mühsam, Martin Buber y Margarethe Faas-Hardegger. Esta última fue una comunidad libre y descentralizada de artesanos, artistas e intelectuales basada en los principios mutualistas como células cooperativistas para la ulterior configuración socialista de la sociedad. ${ }^{8}$

7 Sobre estas cuestiones existe el catálogo de la exposición Expressionist Utiopias: Paradise, Metropolis, Architectural Fantasy de Thimothy O. Benson; y estudios como Noever.

8 La federación vino acompañada de la publicación, hasta 1915, de Der Sozialist. 
De allí que sea posible extender vínculos, frecuentemente negados, entre el expresionismo y la época weimariana; por ejemplo, entre proyectos como la federación de arquitectos Deutscher Werkbund (1907-1938) y la Bauhaus, cuando la Arbeitsrat für Kunst (1918-1921) acogió a personalidades como Walter Gropius. Otras veces, los modelos alternativos derivaron en propuestas cargadas de extravagancia. Podemos encontrar así a futuros adeptos al nazismo en los neopaganistas del Círculo Cósmico de Munich de Alfred Shuler y Ludwig Klages, los Blutleuchte (Luminaria de sangre) o los grupos juveniles antiburgueses de los Wandervögel, todos ellos diferentes entre sí, pero comunes en la época Guillermina en su apuesta por formas de vida alternativa, y por elaborar sus particular "crítica a la civilización" (Frank, Dios en el exilio 244).

\section{Contexto histórico del II Reich a la Revolución a través del Expresionismo}

Hemos expuesto algunas cuestiones relativas al romanticismo alemán en su vertiente de proyecto político. Ahora, centrándonos ya en el contexto finisecular y posbélico, veremos cómo las aspiraciones idealistas siguieron transfiriéndose a la concepción práctica de un nuevo orden social a lo largo de los primeros años del siglo. Al impulso idealista de regeneración que dotó al arte de un rol crítico ante los excesos del positivismo, se sumará el sustrato nietzscheano en auge desde finales de siglo, que estableció muchos de los fundamentos tanto del movimiento antiliberal, autoritario y militarista de la Revolución Conservadora, como de los grupos socialistas y de la izquierda ácrata o mutualista.

El fervor por acabar con las crisis del régimen guillemino provoca una crisis constitucional que enfrentó al rey, al ejército y al ministerio con una mayoría liberal que condujo a algunos a hacer apología de la guerra como fuente reedificadora. Estos aires de radicalidad se extendían por todos los ámbitos sociales y culturales del Reich. En este sentido, es necesario separar los discursos políticos que adoptaron este aire revolucionario al menos entre los de apología bélica y aquellos grupos que se situaban en defensa del pacifismo. Algunos de los pacifistas se aglomeraron bajo revistas filoanarquistas, como Kampf(1902-1905), y más tarde la libertaria Die Aktion (19111932), canalizadora del expresionismo más politizado y pacifista antes y durante la Guerra. Pero también Der Sturm (1910-1932) también expresionista y más dedicada a asuntos artísticos y Die Weissen Blätter o Sirius (1913-1920), con gente cercana a la Liga Espartaquista y cuyo objetivo principal fue el rechazo al conflicto armado para tomar el camino del compromiso político con la intelectualidad nacional y europea. Pero si existen puntos en común entre los conservadores militaristas y dichos grupos a la izquierda fue la voluntad de constituir nuevas formas de vida y nuevos valores culturales bajo la influencia de la moda nietzscheana presente a partir de 1890. 
Las aspiraciones de este espíritu demoledor se cristalizaron en acontecimientos dramáticos bien conocidos, en particular, el asesinato del archiduque de AustriaHungría, Francisco Fernando, y de su esposa, la duquesa de Hohenberg (Renouvin 176), a manos de un nacionalista serbio en Sarajevo. Este suceso desata la contienda del Imperio Austro-húngaro frente a Rusia y sus exigencias sobre la afirmación de los derechos soberanos de Serbia. Ante el enfrentamiento entre ambas potencias, el Reich decide intervenir e impulsar una guerra que mantendría al imperio como su aliado. Debido a las demás alianzas estratégicas entre las potencias imperialistas, Francia, Inglaterra y el Imperio Ruso forman la Triple Entente dispuesta a entrar en el conflicto frente a los imperios centrales. Pero la crisis era de un carácter profundo, más allá de los objetivos imperialistas y coloniales; conflictos internos con múltiples revoluciones sociales y enfrentamientos entre las diversas ideologías que componían la movilización social.

En el plano de los movimientos sociopolíticos de la izquierda, durante los años de contienda, la reivindicación de paz se uniría a las demandas de democratización del régimen. Ello canalizó los esfuerzos de algunos grupos políticos en la búsqueda de nuevas formas de convivencia, sobre todo en el bloque compuesto por la socialdemocracia, los católicos y algunos sectores liberal-progresistas. Pero frente al tímido proceso de reformas gubernamentales, que poco iba a cambiar el paisaje político, emergen las huelgas de los movimientos obreros. La escasez de alimentos y bienes básicos de consumo, fruto de la guerra, conducen a amotinamientos de los propios soldados y buques de guerra negándose a reprimir insurrecciones (Díaz Espinosa 33-4). Dada la urgencia del momento y frente a la previsión del desastre de la pérdida de la guerra, el Reichstag inicia la parlamentarización del régimen, llamando a los socialistas a participar en el gobierno. Este factor los obliga a pactar con los demás sectores políticos para la modificación de la Constitución Imperial de 1871 y el establecimiento de una monarquía constitucional parlamentaria. Ante las pretensiones de mantener al Kaiser en el poder, el 9 de noviembre de 1918 entran en acción más movimientos revolucionarios. Formados por soldados y trabajadores, las movilizaciones conocidas como la Revolución de Noviembre se extienden por todo el país generándose consejos obreros en todas las ciudades y exigiendo el armisticio, la paz y la abdicación de Gillermo in de Prusia.

Estos acontecimientos, detonados por la Revolución de Noviembre, abrirán paso a la vía republicana con la ascensión al poder de los socialdemócratas del SPD con una fuerte oposición del ala izquierda de los socialistas independientes pidiendo reformas más radicales como la organización por consejos o soviets (los Rät), en consonancia con lo ocurrido en la Unión Soviética. Tensados ante las propuestas parlamentaristas, los independientes junto a la escindida Spartakusbund liderada por Karl Liebknecht y Rosa Luxemburgo propusieron la plena socialización de la industria y una no-colaboración con la burguesía. Anexionados posteriormente al Partido Comunista alemán (KPD), los espartaquistas confiaron en una prolongación de 
la revolución más allá del 9 de noviembre. Sin embargo, tan solo a un mes vista de las primeras elecciones, las alianzas de paz se rompieron y se levantaron movilizaciones revolucionarias, cuya represión acabó con el asesinato de Rosa Luxemburgo y Karl Liebknecht en enero de 1919, y en mayo, con el de Gustav Landauer, todos ellos a manos de los Freikorps (Díaz Espinosa 57-61).

Tal como introduce el análisis de Joan Weinstein, las fases y historiografía de la revolución y sus vínculos con el campo artístico son complejos, a pesar de que si bien ell período revolucionario se divide en varias fases y núcleos, ocurre en unos pocos meses (Berlin, Munich, Dresde). En ellos se dibujó la primera euforia revolucionaria y teórica hasta el ulterior fracaso del expresionismo en vehicular propuestas concretas que salvaran sus propias contradicciones, como por ejemplo, sus postulados ácratas y el sostén artístico mediante la economía de mercado existente (6).

\section{La politización del Expresionismo a través de Nietzsche}

Si bien muchos actores de la revolución provenían del magma expresionista, este movimiento no puede considerarse como explícitamente politizado más allá de su oposición a los valores morales burgueses y al racionalismo, al patriotismo de la academia o su adscripción a un amplio concepto de arte libre y primitivista -tal como sucede en el entorno de Die Brücke (1903-1913) y que, a pesar de ello, encontrará apoyo en el mercado artístico justo antes de la Guerra (Weinstein 8)-. Salvo contadas excepciones -como las de Erich Mühsam-, no será hasta después de la contienda que los expresionistas se inmiscuyan de forma plena el debate en torno a la función y situación del arte en la política revolucionaria. Mühsam fue un escritor independiente que provenía de la escena del cabaret de Berlín y de la publicación Die Aktion; ${ }^{9}$ fue fundador del Gruppe Tat (Grupo de Acción para la agitación y propaganda anarquista), siguiendo la Liga Socialista del literato Gustav Landauer; fue agente activo en los consejos de la Räterepublik de Munich como dirigente, y, aunque es obvio -ya podíamos ver un claro guiño a Nietzsche y a Así hablo Zaratustra en el grupo Die Brücke o El Puente-, ${ }^{10}$ Müsham será el salvoconducto entre las derivas espirituales del expresionismo y las posteriores propuestas revolucionarias de inspiración nietzscheana.

9 Otros artistas vinculados al expresionismo que sí incluyeron motivos explícitamente políticos en sus obras fueron: Ludwig Meidner con el óleo llamando a la revolución Barrikadenkampf de 1912 y Apokalyptische Landschaft de 1913. En el núcleo de Múnich se dieron propuestas artísticas cooperativas en el ámbito del cabaret y de rechazo al mercado artístico con el proyecto de Kandinsky Phalanx. Algunas vinculaciones al sPD de artistas o promotores como Wilhelm Hausenstein o la publicación de Mühsam Revolution en 1913 siguiendo los preceptos de la Sozialistische Bund.

10 "La grandeza del hombre está en ser un puente y no una meta: lo que en el hombre se puede amar, es que es un tránsito y un ocaso. Amo a quienes no saben vivir de otro modo que hundiéndose en su ocaso, pues ellos son los que pasan al otro lado" (Nietzsche, Así habló 4). 
Tal y como advierte Taylor, la lectura de Nietzsche durante finales del xix y principios del xx por parte de la intelectualidad alemana fue siempre parcial. Por lo tanto, señalamos ya de entrada que se tratará más de analizar la asimilación de ciertos conceptos filosóficos por parte de las figuras relevantes del expresionismo y su reelaboración como herramienta política o teórica, antes que de un estudio sistematizado de su legado.

A grandes rasgos, los ejes heredados de esa lectura se sostienen, paradójicamente, en la postura antipolítica de Nietzsche, crítica a la democracia parlamentaria, es decir, crítica ante liberalismo imperialista del Reich y sus instituciones. Uno de los primeros textos que justifican desde el flanco conservador esta posición antidemócratica fue el manifiesto de 1917 de Thomas Mann, Consideraciones de un apolítico:

El imperialismo de la civilización es la forma última de la idea romana de unificación contra la cual protesta Alemania; y contra ninguna de las formas en las que se manifiesta lo ha hecho más apasionadamente, contra ninguna de ellas ha tenido que librar una lucha más terrible que contra esta (70).

Por otra parte, la crítica del lenguaje alimentará el rechazo ante presupuestos teóricos del marxismo y su falsa neutralidad respecto de valores éticos y convencionalismos morales; mientras que el irracionalismo vitalista, en nexo con el individualismo idealista presente en el Ecce Homo o en el Zaratustra -y en sentido inverso a la apropiación de la derecha-, se convertiría en un fértil campo para vehicular la oposición al utilitarismo, al autoritarismo y militarismo de las instituciones alemanas, fuera del gobierno o del mismo partido. Ligado al irracionalismo y dejando a un lado otras lecturas posibles, habría que considerar el papel redentor del arte, dimensión en que Nietzsche juega un papel relevante en la recuperación de los postulados románticos respecto del retorno de dioses mesiánicos en tanto fundadores de nuevas comunidades. Tal y como ha sido desarrollado por Mandfred Frank, ${ }^{11}$ los mitos sirven para garantizar la permanencia y constitución de una sociedad a partir del consenso y unanimidad de sus miembros en torno a determinados valores supremos. Hemos visto ya la importancia dada a las ideas estéticas en el contexto alemán. El arte continuaba siendo un elemento capital a la hora de fundamentar la mitología del proyecto político moderno. En lo que fue la Noche de los Dioses cantada por Novalis, Hölderling, Schelling, Gotthilf Heinrich Schubert o Ludwig Tieck, Dionisos encarnó el renacimiento espiritual y de afirmación de aquello situado más allá del conocimiento lógico. Con la esperanza de poder superar la crisis de sentido de la modernidad, Dioniso se adecuaba como metáfora perfecta

11 Frente a la vacuidad de la razón, la refundación de una nueva mitología profana servía a idealistas y románticos alemanes (Novalis, Shelling, Schlegel, etc.) para reinstaurar los valores y dotar de sentido la existencia basada ahora en una convivencia y consenso universal. Un estudio sobre el amplio espectro neomitológico de los románticos junto a otro centrado específicamente en el retorno de Dionisos durante el siglo xx prefascista puede encontrarse en las dos obras de Mandfred Frank, El dios venidero. Lecciones sobre la nueva mitología y el ya mencionado Dios en el exilio. 
del dios venidero. En tanto que dios extranjero, renacido, mistérico, aniquilador de límites, dios de la multiplicidad y el exceso, en el siglo xix, el dios asiático encarnaba una revisión del cristianismo, en calidad de una nueva religión. En este sentido fue Nietzsche quien, desde 1871, casi un siglo después, vuelve a condensar la carga radical contra la modernidad a través del interés por el "renacido" y el impulso vitalista. Podemos situar el estudio no filológico sobre el Origen de la tragedia en tanto bisagra entre el influjo romántico de finales del xvin y las manifestaciones artísticas que alimentarán la primera postguerra. Y resaltamos el componente no académico de la obra, porque al igual que en la romantización de la historia de Novalis, Nietzsche proponía "considerar la ciencia con la óptica del artista y el arte con la óptica de la vida" (35).

El culto a Dionisos -el ser del sí eterno, del deseo de vida-, a esa pulsión irracional no mediada por instrumentalismos o fines más allá de sí misma, dinamitaba los valores modernos -la moral, la democracia o el capitalismo-. Es a través del ritual artístico que "cantando y bailando, el hombre se siente miembro de una comunidad superior: ya se ha olvidado de andar y de hablar, y está a punto de volar por los aires, danzando" (Nietzsche, El origen 52).

La exaltación artística y la carga mística abolían así la finalidad -que es siempre finalidad de la razón-, y afirmaba el juego azaroso de la voluntad, el éxtasis no mediado de cada hombre. Uno que se reconcilia consigo mismo y con la naturaleza enajenada, enemiga o sometida, es decir, sometida a la razón utilitaria. Muchas de las ideas nietzscheanas -como la de acción creadora, la ruptura de límites representacionales, la relevancia que tomaron las instancias noracionales y el arte como vehículo refundacional- se diseminaron más allá del modernismo finisecular. En el caso de la Räterepublik, la lucha germana de la Kultur contra la civilización invasora francesa, el instinto irracional era sustituido ahora por una nueva y paradójica articulación, la pulsión irracional de vida como vehículo de consenso comunitario para la implantación de la razón marxista.

En este sentido, fue el ensayista Kurt Hiller - desde el comunismo y los núcleos esenciales de las revistas Der Sturm y Die Aktion- quien más trabajara en el influjo nietzscheano hacia el expresionismo (Taylor 60). Inspirado principalmente en el vitalismo, fomentó el entusiasmo por constituir un orden social nuevo y racional, y como factor de cohesión y consenso de masas contra las políticas bélicas e imperialistas. Es decir, un irracionalismo místico puesto al servicio del racionalismo ético. La contradicción a resolver en el espectro de los expresionistas y del mismo Hiller, por tanto, sería aunar el fuerte componente individualista con el compromiso para con el cambio social de la democracia radical y con una necesaria articulación con la política de base. Ello se negociaría a través del concepto de Geist-alma o espíritu ligado a la voluntad de poder-, pero desechando la interpretación aristocrática de Geist, entendida como actitud de la clase política dirigente que podría conducir a concepciones autoritaristas. Este será un escollo teórico derivado del fundamento nietzscheano que volveremos a encontrar en Landauer y que, mediante la asimilación del Geist 
como representante de la libertad del sujeto a favor de la solidaridad comunitaria, se haya presente en cualquier clase social. Nietzsche entendió al artista como un agente creador de un mundo nuevo, un nuevo Geist, principio al que el pueblo debe aspirar. Es más, en un momento dado, los artistas, convertidos en una clase bohemia, estarían por encima de las líneas de partido para catalizar y guiar la acción política. En estos autores, el Geist en tanto herramienta política, aspira a una sociedad sin estado y sin violencia, dotando la acción social de una base moral pacifista e incluso feminista (Helene Stöker), que abriría un espacio de crítica al marxismo ortodoxo, al leninismo y a lo que denominaron la "violencia roja" en revistas afines como Ziel (Taylor 77). En la estructura jurídica de la Räterepublik, ello se traduciría en la propuesta de una doble cámara legislativa en donde la cámara de diputados electos sería vigilada por la Rät geistiger Arbeiter (Consejo de Obreros Intelectuales). Tal modelo fue aceptado, finalmente, de forma laxa como órgano consultivo formado por la élite intelectual en ciudades como Viena, Munich, Leipzig o Dresde donde la primacía la tuvieron los consejos obreros (Taylor 82).

A pesar de tales esfuerzos, tras la muerte del expresionismo muchos críticos, como Georg Lukács en Asalto a la razón, señalaron cómo ese rol del Geist irracionalista liderando a una elite ilustrada hacia la revolución se acababa convirtiendo en el camino premonitorio hacia el fascismo.

Igualmente, en otras figuras difusoras del pensamiento nietzscheano, como fue el psicoanalista Otto Gross, influyente en el círculo expresionista que estuvo presente en Múnich y decisivo en el pensamiento de Eric Müsham y el grupo Tat, volvemos a encontrar la problemática filosóficas a la hora de articular las nociones libertarias y derechos individuales con la idea de una comunidad colectivista inspirada en la Voluntad de Poder (Taylor 103).

Vamos a ver ahora cómo uno de los momentos pragmáticos en la incorporación del irracionalismo nietzscheano en la concepción política y artística del nuevo orden social parte de estas figuras vinculadas a la política de la Räterepublik de Munich, como Eisner, Mühsam y Landauer. ${ }^{12}$

\section{La política cultural de la Räterepublik}

El caso de la Räterepublik de Munich o República Soviética de Baviera es un buen ejemplo para analizar las propuestas de reformulación del marxismo a través del sustrato idealista y nietzscheano. Abordando más en detalle los acontecimientos, el 7 de noviembre de 1918 en Múnich, a raíz de una manifestación pacifista organizada por el SPD en Baviera, se formó el primer Consejo de Obreros, Soldados y Campesinos

12 Seth Taylor sitúa otras figuras concretas en la re-elaboración de Nietzsche, entre muchas otras, Salomo Friedlaender y Anselm Ruest. 
-tal y como sucedió en otros territorios del Reich, tras la Revolución de Noviembre- bajo la dirección de Kurt Eisner. ${ }^{13}$ Por aquel entonces Eisner era dirigente de la escisión de socialistas independientes USPD y había entrado en contacto con Landauer a principios de siglo en el círculo de la Neue Gemeinschatf (Nueva Comunidad). ${ }^{14}$ Frente a las agitaciones políticas del noviembre revolucionario, Luis III de Baviera había abandonado la ciudad, por lo que se convierte en el primer monarca depuesto por una revolución alemana. Se proclamó la República de Baviera o República de Consejos de Múnich y ese mismo día se formó un nuevo gobierno con una coalición entre socialdemócratas y radicales independientes. La Revolución Bávara se divide en cinco fases diferenciadas: una primera marcada por la supresión de la monarquía con la temprana muerte de Kurt Eisner por los militares contrarrevolucionarios a principios del 1919; una segunda, liderada por el intento del Consejo Central de reafirmar el movimiento; la tercera, con el gobierno socialista de Johannes Hoffmann intentando recomponer el parlamento; la cuarta, definida por una Räterepublik de tendencia anarquista; y la quinta, dominada por los comunistas (Lamb 173-209). En su totalidad abarca un periodo que se extiende desde noviembre de 1918 a mayo de 1919 cuando el gobierno es depuesto violentamente por los Freikorps.

Algunos de los responsables de este movimiento de consejos fueron, como hemos señalado, figuras con un pie en la política y otro en la cultura. Enlazando con el sustrato filosófico del siglo xIx, cuando los artistas convirtieron el arte en "algo tan serio" como la política, la Räterepublik intentaría romper con la tácita separación entre la esfera de la cultura y la esfera de la política gubernamental, dotando al arte de un rol activo en la revolución. Los actores principales en esta tarea fueron el mismo Kurt Eisner, al comienzo del proceso, con un programa inspirado en Las cartas de la educación estética de Schiller; Gustav Landauer; Erich Mühsam y otros, como el poeta y dramaturgo Ernst Toller, quien acabaría siendo presidente del Consejo Central con tan solo veinticinco años o, entre los consejos obreros, un joven Bertolt Brecht.

Tras los intentos por aprovechar lo que sería la última oportunidad alemana de generar una democracia de base la Räterepublik de Munich supuso el intento por redefinir la política parlamentaria por parte de un determinado grupo de intelectuales alemanes, y por lo tanto, de superar la artificial distinción entre teoría y práctica que había caracterizado a la Geistesgeschichte (historia intelectual) alemana al menos desde Kant (Lamb 179).

Es decir, frente la pervivencia de la problemática alemana sobre la dialéctica kantiana querer-deber, la Revolución bávara fue un intento por llevar a la praxis política y al terreno del movimiento obrero las tesis idealistas de Schiller y ciertos postulados

13 Las obras más relevantes de Eisner fueron Fester der Festlosen y Die Götferprüung. En español existe solo la traducción de 1920 de La revolución alemana.

14 Movimiento alternativo de orientación ecologista fundad por los hermanos Heirnich y Julius Hart. Según Kauffeldt, la Nueva Comunidad fue un punto culminante de las innovaciones intelectuales y artísticas que conducirán a la vanguardia del siglo xx (Kauffeldt 155). 
románticos sobre la libertad individual y creadora. El ejemplo determinante en este intento por superar los lastres que criticara Marx sobre el idealismo, se halla en el personaje de Kurt Eisner, ${ }^{15}$ quien en tanto defensor del modelo de consejos trataría de acabar con la distinción entre pensamiento y acción. Con un socialismo tachado de ético y estético, caracterizado como Belletristik, Kurt Eisner se proclama como primer ministro de la República de Baviera, concediendo un lugar prominente a la política cultural y social. Heinrich Mann, en su funeral, declaró: "Los cien días de gobierno de Eisner han producido un más placentero ejercicio de las facultades racionales del hombre, más rejuvenecimiento del espíritu que los cincuenta años anteriores" (cit. en Lamb 181). Eisner intentó configurar aquel Rät geistiger Arbeiter (Consejo de Trabajadores Intelectuales) caracterizado "por el exceso de retórica frente al debate práctico a través del cual la revolución bávara, quizás la primera en la historia del mundo que une el ideal y la realidad, sería un cuento de hadas que se hace realidad" (Lamb 189).

En Eisner, politizar la estética, debería conducir a una reespiritualización que educase y elevase a las masas, aunque, esta vez, el Kulturstaat se llevara a cabo además por la vía revolucionaria y no únicamente por la vía literaria, logrando así la unión entre cultura y política revolucionaria. Pensemos que la idea de Kultur había sido cooptada por las instituciones artísticas guilleminas y por la derecha conservadora. La crítica antimoderna del filósofo contra el control gubernamental del Reich sobre la educación, contra el carácter mercantil de la cultura o como recreación personal y elitista, alimentará las posturas del movimiento consejista ante lo artístico. ${ }^{16}$ Ello no quiere decir que el mismo expresionismo o movimientos adyacentes -a pesar de su carácter marginal- no hubiesen participado de ciertas estructuras de mercado; de hecho, las políticas de Eisner en torno a lo artístico supondrán un conflicto con muchos de los grupos artísticos que participaron en el movimiento de consejos.

Eisner introdujo por vez primera en el parlamento el asunto del "Arte alemán” a través del programa expuesto en "La actitud del Gobierno Revolucionario en torno al Arte y los Artistas" (Eisner, Sozialismus; Weinstein 164). El principal objetivo de Eisner era acabar con la autonomía del arte integrándolo en los procesos productivos y como agente activo en el nuevo estado de consejos pero manteniendo siempre su libertad frente al control del Estado. En definitiva, la postura de Eisner era la de confinar el arte al entorno de la artesanía. De este modo, absorbiendo el liberalismo subjetivista del idealismo y extendiéndolo a una política no intervencionista que permitiese un desarrollo pleno de la autonomía individual, Eisner se situaba en la posición contraria al sistema artístico del antiguo Reich, basado en la censura y el sistema académico,

15 Un estudio detallado sobre la relación entre Eisner y la revolución bávara se encuentra en Mitchell. En alemán está publicado el discurso de Eisner sobre "La actitud del gobierno revolucionario para con el arte y los artistas" en Sozialismus als Aktion.

16 Con todo, el gobierno de Eisner tubo ciertos resultados concretos: su política basada en una gradualidad en la construcción del socialismo y el principio de gobierno por consenso lo acercaban más a la socialdemocracia que al comunismo o al anarquismo. 
la credencial o en la subvención estatal. De este modo, se despachaba el modelo crediticio de las viejas instituciones. Ello acababa derivando en la negativa a un sistema de subvenciones y a la eliminación del objeto artístico como mercancía de lujo. Este modelo no encajaría con las demandas del organismo encargado de representar a los artistas: el Consejo Münchner Neueste Nachrichten. El Consejo daba cobijo a los grupos artísticos formados en la región bávara tras la revolución: Wirtschaftsverband bildender Künstler (Asociación Profesional de Artistas Visuales), Bund zeichnender Künstler (Federación de Dibujantes), Die Juryfreien, Illustratorenverband (Asociación de Ilustradores), Künstlergenossenschaft (Asociación de Artistas), Künstlerinnenverein (Asociación de Mujeres Artistas), Luitppoldgruppe (Grupo Luitppold), Radierverein, la Secession y el Münchner Bund al que posteriormente se añadirían Münchener Neue Secession y Grouppe 100 (Weinstein 161-218). A pesar de todo, el espectro de propuestas de los agentes artísticos y sus propuestas políticas era muy variado en Munich y no se puede someter a un único paradigma. ${ }^{17}$

En esta línea, grupos como el Aktionsausschuss revolutionärer Künstler (Comité de Acción de Artistas Revolucionarios) también recogían la tradición de Saint-Simon, Charles Fourier y Morris en la revitalización del artesanado - presente, por ejemplo, en la explotación de la litografía como sucedía con el expresionismo- como forma de oposición a la producción capitalista y como forma de inclusión del arte en la vida cotidiana. Si podemos destacar un lema general en todo este informe conjunto de propuestas que van desde el expresionismo (Max Pechstein y Cesar Klein) al activismo social (Käthe Kollwitz), a los miembros de la Freie Secession (como el impresionista Theo von Brockhusen) o hasta la arquitectura utópica de Bruno Taut, es el de la democratización del arte y la descentralización institucional.

En mayo, Eisner propuso como comisario de cultura a otro componente de este grupúsculo de letrados: Gustav Landauer. Ligado al anarquismo comunitario, había dedicado su carrera a la traducción de Kropotkin, Proudhon y Oscar Wilde, y elaboró una reformulación del socialismo a través del romanticismo y la mística medieval del Maestro Eckahrt. Su desconfianza tanto de la autocracia guillemina como de las aspiraciones socialdemócratas o de la comunista dictadura del proletariado le llevaría a posicionarse ya desde un inicio fuera de la ortodoxia marxista gracias al influjo nietzscheano y variadas fuentes. Rechazó la estrategia del Partido Comunista en uno de sus más celebrados textos antes de la revolución: Incitación al socialismo. ${ }^{18} \mathrm{Su}$ idea

17 Hay que recordar también el resto de grupos artísticos derivados de la Revolución de Noviembre que se extendieron por todo el territorio alemán, como el Novembergruppe, Arbeitsrat für Kunst (Consejo de Trabajadores para el Arte), fundado por Bruno Taut y Adolf Behne en Berlín, el Bund Radikaler Künstler (Asociación de Artistas Radicales), el Dresdner Sezession Gruppe o el Aktionsausschuss revolutionärer Künstler (Comité de Acción del Arte Revolucionario) en Munich, provenientes del círculo de Die Aktion. Una recopilación de manifiestos de algunos de estos movimientos se hallan publicados en Washton Long.

18 De su Incitación al socialismo de 1911, uno de los pocos textos publicados en español en 1931, se ha considerado que junto al texto de Heinrich Mann Espíritu y acción conforman los dos escritos programáticos para la autocomprensión intelectual del expresionismo (Kauffeldt 144). 
FIGURA 1

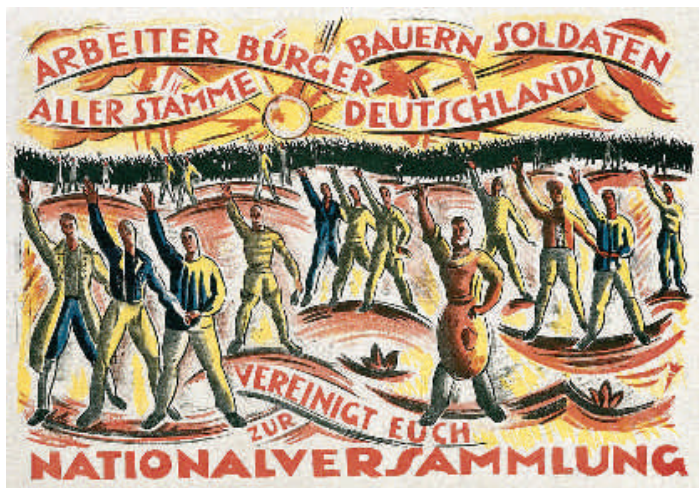

Arbeiter. Bürger Bauern. Soldaten aller Stäemme Deutschlands vereinigt Euch zur Nationalversammlung (Los trabajadores, soldados, agricultores y ciudadanos se unen en la Asamblea Nacional), 1918; y a la derecha, Wer nicht arbeitet ist die Totengräber seiner Kinder (El trabajador que no trabaja es el sepulturero de sus hijos), de Cesar Klein, 1919.

\section{FIGURA 2}

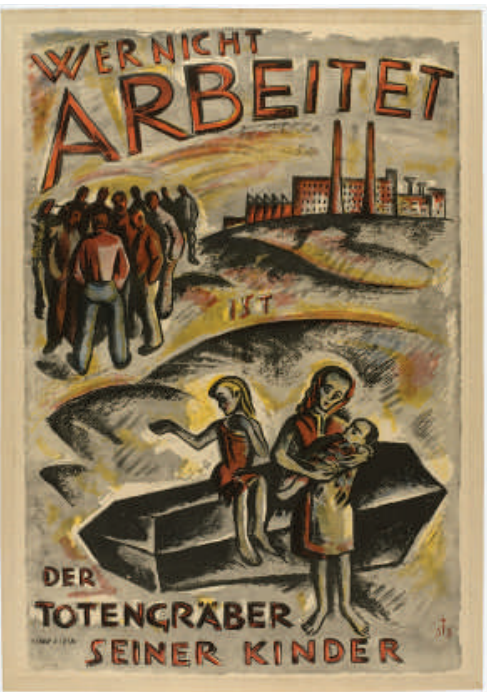

FIGURA 3

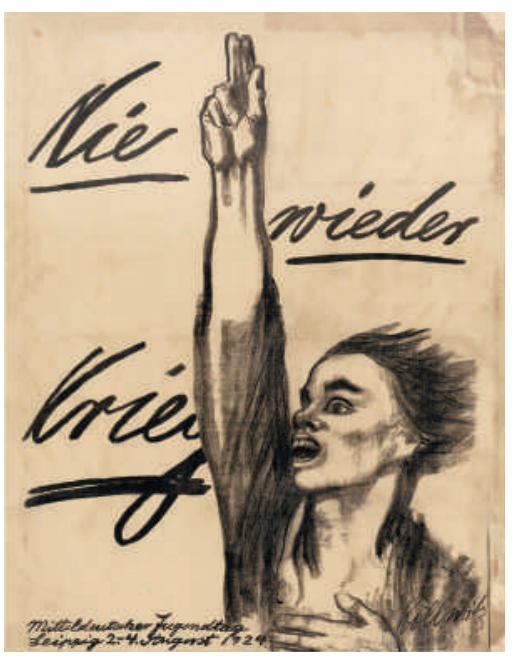

\section{FIGURA 4}

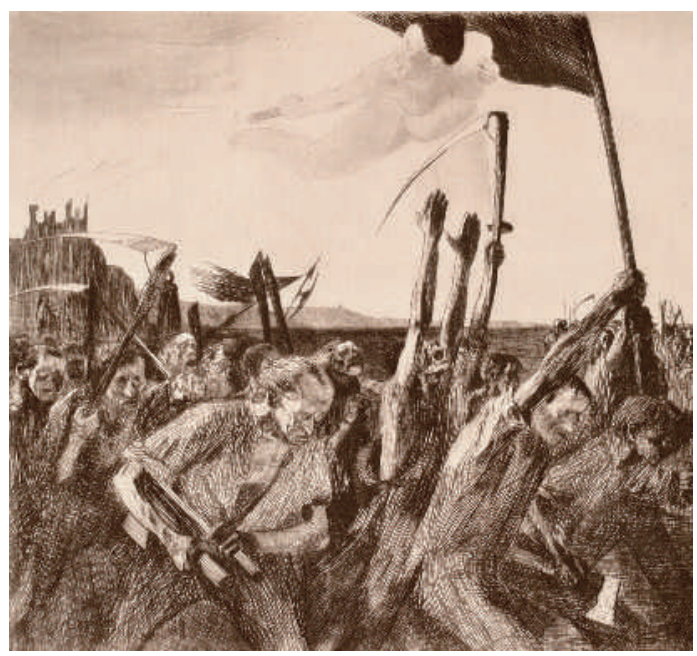

Octavilla Nie wieder Krieg (Nunca más la guerra), 1924; grabado Aufruhr (Revuelta), de la artista Käthe Kollwitz, 1899.

era poner en práctica una comunidad basada en una estructura social federalista y cercana a la idea del socialismo voluntarista donde la revolución no iba articulada a la idea soviética de destrucción sino a la reconciliación orgánica entre religión, cultura y economía. Defendiendo la idea de un "renacimiento mitológico", Gustav Landauer también sería uno de los puntos de fuga ante la dicotomía socialdemócrata y la derecha antiliberal (Kauffeldt 139). 
FIGURA 5

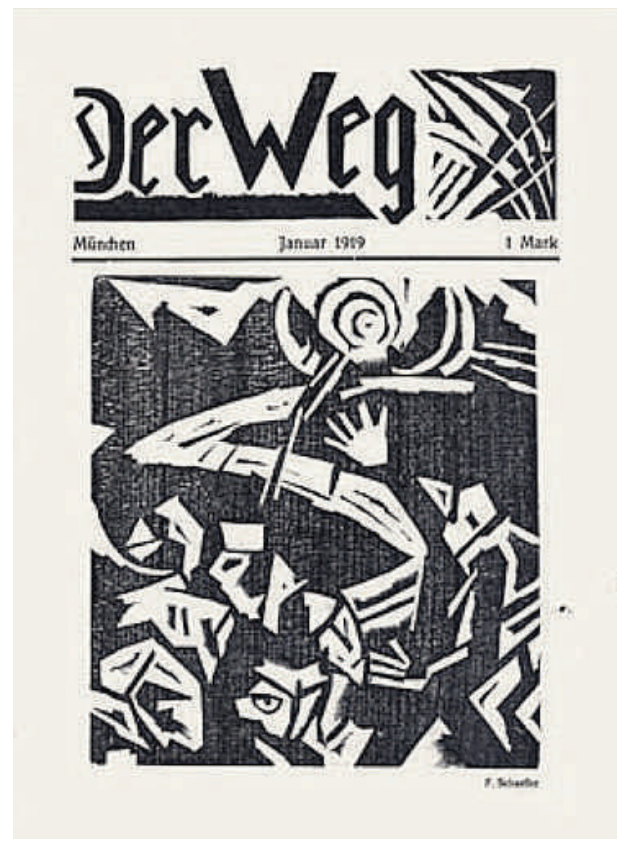

FIGURA 6

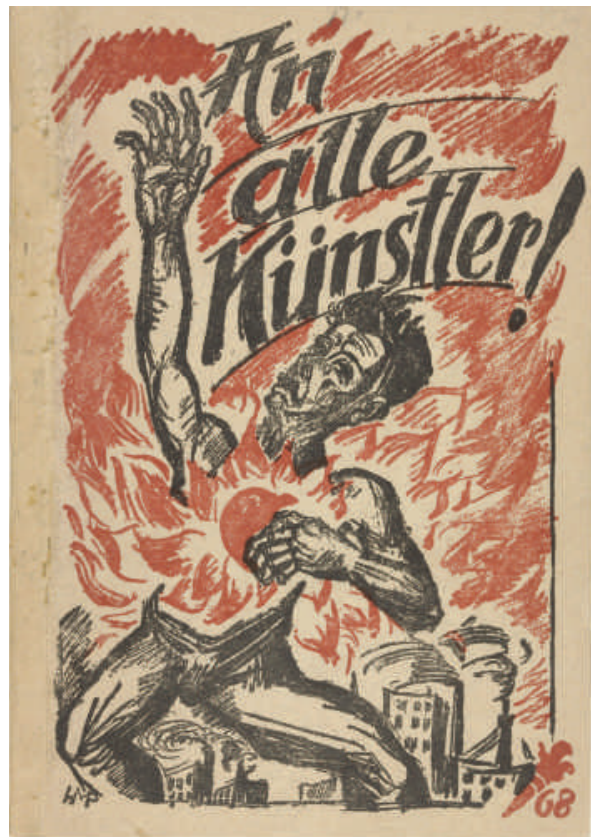

A la derecha, portada de Fritz Shaefler del no 1 (1919) de la revista de tendencia anarquista y revolucionaria, Der Weg, una de las aparecidas tras la revolución de Noviembre y que comprendía tanto artículos políticos como artísticos. A la izquerda, un panfleto revolucionario de Max Pechstein An alle Künstler! (1918) (¡A todos los artistas!) desde Novembergruppe incitando a la revolución. El panfleto se encargaría de difundir las diversas propuestas políticas de los grupos artísticos y el programa de Eisner en Munich "La actitud del Gobierno Revolucionario en torno al Arte y los Artistas".

Dejando de lado la cantidad de proyectos políticos y movimientos culturales vinculados a los postulados de Landauer, ${ }^{19}$ mencionaremos aquí algunas de sus concepciones políticas en el contexto revolucionario sobre el arte y su posibilidad de transformación social que no tuvo posibilidad de llevar a la máxima sus postulados puesto que fue asesinado por las tropas blancas, pocos meses después de su nombramiento como comisario del pueblo para la instrucción pública.

Parte del cuerpo teórico de Landauer consistió en una deriva de Pierre Lerroux y de las ideas esbozadas en el primer Wagner en El arte y la revolución, pasando después desde Nietzsche y Spinoza al misticismo de Eckhart, todo esto con vistas a

19 Gustav Landauer escribiría tanto sobre temas culturales como políticos, influyendo de forma directa sobre la teoría de cooperativas de urbanización, en el movimiento de asentamientos sionistas en Alemania y Palestina: los kibutz socialistas y sobre el movimiento judaico-revolucionario de la Nueva Comunidad. La Neue Gemeinschaft, fundada en 1900 por los hermanos Heinrich y Julius Hart, es otro de los proyectos ecológicos y filosógicos-naturalistas para la práctica de una "nueva vida", que intentaría fundar una comuna lejos de la ciudad industrializada y sobre una base comunitarista. Sobre los textos políticos de Landauer desde sus inicios hasta la Räterepublick existe un compendio en inglés de artículos publicados en prensa traducidos y editados por Gabriel Kuhn. En español solamente la citada Incitación al socialismo y La Revolución. 
realizar una crítica a la filosofía racionalista de Kant, Berkeley o Locke. La primera síntesis de socialismo y Nietzsche la realizó en su novela Der Todesprediger. Landauer influiría también a Ernst Bloch y a muchos de los artistas de Weimar. Colaboró con Fritz Mauthner en su obra Contribuciones a una crítica del lenguaje, donde el arte se convierte en el vehículo posible para la comunicación en tanto vía de expresión de lo inefable, conjunción del interior subjetivo y de una reconceptualización de Dios y lo eterno. De este modo, los tratados de Landauer vuelven sobre el primer Romanticismo alemán.

En su prolífico texto Durch Absonderung zur Gemeinschaft (Separación a través de la comunidad), Landauer (97) elaboraría un programa de estrategia revolucionaria alternativa. En este caso, se trataba de la recuperación del Romanticismo y el mesianismo judío como "vida y revuelta", potencia subversiva y activista, bajo parámetros primero socialistas, y luego anarquistas, con los que intenta impulsar su curso hacia efectos prácticos. Pensemos que uno de los objetivos principales del romanticismo revolucionario de Landauer era, precisamente, deshacerse de los atisbos utópicos y demostrar que la realización del socialismo era posible. Esta sería la principal motivación de su proyecto Alianza Socialista, que preveía la construcción de comunidades confederadas y colonias autorganizadas en el "aquí y ahora”. Este marco organizativo para el llamado "socialismo de la realización” y "revolución voluntarista”, contrario al desarrollo marxista paulatino, se transferiría como base ideológica para la Rätrepublik.

En Separación a través de la comunidad intentó a su vez resolver uno de los mayores escollos nietzscheanos, el de la dicotomía entre una elite de vanguardia y la masa social. La actitud de vanguardia la vinculó a un estado del espíritu -de nuevo Geist- no asociado a ninguna clase estamental, sino una predisposición mística. Para alcanzar la nueva comunidad era necesario reencontrarse con aquellas formas más antiguas y completas de comunidad donde el individuo conectaba con lo universal, ergo con la humanidad. Mundo y sujeto, percepción del mundo y acción sobre él, al igual que la idea expandida de Dios de Spinoza, fueron para Landauer una misma cosa. De este modo, el sentirse en conexión a las causas y efectos de la realidad, se proporcionaba un sentimiento de unión y solidaridad con el resto de seres vivos. Esta era la vía para la realización del proyecto socialista, la crítica a la separación entre alma y mundo de la secularización moderna:

Debemos darnos cuenta de que no nos limitamos a percibir el mundo, sino que somos el mundo. El ahora como instante eterno, hacer presente y real la comunidad de un pasado mítificado. Lo comunitario en Landauer se convertía en una afirmación del indivíduo cuya naturaleza viva, por tanto, activa con y en el mundo, en una superación de la alienación moderna, establecía nuevas connexiones comunitaristas que hacían posible el proyecto socialista: A través de la separación de la comunidad: lo que esto significa es: vamos a arriesgar todo, para que podamos vivir como seres humanos completos (Landauer, Revolution and Other 94, 109). 
La Revolución Bávara -tal como indica Eugene Lunn (219)- sirvió al socialista independiente para llevar a cabo un modelo federalista de comunidades locales autorganizadas, aboliendo la idea de clase e implicando a toda la comunidad en su gobierno. Es decir, comunidades con una democracia de base y descentralizada (no parlamentarista), algo que no tuvo respuesta por parte de la sociedad alemana. $\mathrm{Su}$ alejamiento del comunismo le conducía a rechazar también sus herramientas conceptuales, abogando no por una dictadura del proletariado, sino por la abolición del proletariado en sí mismo (Lunn 301). En este sentido cabe aludir al peso de la crítica nietzscheana del lenguaje en tanto fundamento para rechazar conceptos naturalizados por el marxismo y cualquier herramienta política preconcebida como ente autoritario o trascendente, sea el Estado o la democracia parlamentaria. El sentido último que otorga la vehiculación política a Landauer será precisamente esa componente irracional de mística asociada al romanticismo, y que hemos visto también presente en El origen de la tragedia. En su Discurso a los poetas, sostiene:

Sin embargo, nosotros necesitamos en verdad la renovación que siempre retorna, necesitamos la disponibilidad a la conmoción, necesitamos la gran llamada de la seisachtehia a través de los campos, necesitamos la trompa del pastor Moisés, que de tiempo en tiempo convoca al gran año jubilar, necesitamos la primavera, la locura y la ebriedad y el frenesí, necesitamos - una vez y otra y otra- la revolución, necesitamos al poeta (cit. en Kauffeldt 183).

\section{Conclusión}

A través del caso de la Räterepublik hemos visto cómo opera la incorporación de la tradición romántica en la refundación mística del contrato social y rechazo del modelo parlamentarista. En ese ejercicio por conectar la tradición romántica con los hechos históricos sucedidos tras la Primera Guerra Mundial, hemos visto cómo la relectura de las ideas estéticas de Nietzsche alimentaron no solo la antipolítica de tendencias conservadoras sino que también la creación de una alternativa progresista entendida como crítica tanto a los excesos del irracionalismo conservador de la derecha -también lector de Nietzsche- como al utilitarismo burocrático, incluso contra las posiciones de la socialdemocracia o del KPD. En nuestro recorrido por las ideas estéticas que tomaron relevancia especial en el corpus político de la pretendida revolución, podemos señalar que fue a través de una filosofía crítica no adscrita al racionalismo como se intentó superar la dialéctica moderna entre secularización social y vínculos comunitarios.

Es interesante comprobar cómo, fuera del núcleo de la revolución conservadora que acabará confluyendo en el nazismo, en el reclamo para la creación de un modelo de producción alternativo a las relaciones capitalistas, el factor irracionalista se incorporó también en discursos que pretendieron superar el factor utopista. Las 
propuestas del entorno politizado expresionista siguieron un estrecho vínculo con la tradición del socialismo utópico y el mutualismo; sin embargo, tal y como hemos señalado, curiosamente la relectura política de Nietzsche sirvió en la configuración de un irracionalismo místico puesto al servicio del racionalismo ético. Será esa tradición la que de una forma u otra, durante los años de la República de Weimar, servirá como eslabón crítico a figuras conflictivas dentro de la corriente de pensadores de la izquierda como Walter Benjamin o Ernst Bloch. Estas figuras heterodoxas se preocuparon por el carácter mítico de la cultura, asumiendo la crítica a la idea de progreso como fin en sí mismo al mismo tiempo que constituirán una crítica al también mito racionalista moderno "que reduce todo trabajo a lo técnico" (Benjamin 21) y que desterraba el humanismo que "fundamenta religiosamente nuestra vida de comunidad" (Benjamin 22). Por ejemplo, la crítica de Bloch al comunismo irá dirigida al gran descuido del partido ante el deseo que moviliza al sujeto. Al despreciar el componente mítico que subyace a toda política, como relato de esperanza, el comunismo era responsable de su propio fracaso ante el avance fascista. Bloch situó el principio de esperanza que constituye nuestra relación con el mundo presente como un elemento constitutivo de la consciencia, es decir, como proceso constitutivo del orden simbólico y no simplemente como mero deseo de retorno a un pasado premoderno y utópico. En este sentido, y en mayor o menor medida política o literaria, tales acontecimientos revolucionarios como el Romanticismo o la Revolución de Noviembre proponen tanto disrupciones de sentido como nuevas místicas que iluminaran otras y nuevas posibilidades para pensar sobre la articulación entre arte y política en una más amplia acepción del binomio.

\section{Bibliografía}

Benjamin, Walter. "Diálogo sobre la religiosidad del presente". Obras Completas.

Ed. Rolf Tiedemann y Hermann Schweppenhäuser. Madrid, Abada Editores, 2010, pp. 17-35.

Benson, Thimothy O. Expressionist Utiopias: Paradise, Metropolis, Architectural Fantasy. Los Angeles, Los Angeles Conty Museaum of Art, 1994.

Bloch, Ernst. Heritage of our Times. Cambridge, Polity Press, 1991.

---. The Principle of Hope. Cambridge, mit Press, 1995.

Cirlot, Lourdes. "El Maestro Eckhart y la arquitectura de Bruno Taut". Mística y creación en el siglo Xx. Tradición e innovación en la cultura europea. Ed. Lourdes Cirlot y Amador Vega. Barcelona: Herder, 2006, pp. 199-240.

Díez Espinosa, José Ramón. El fracaso de una ilusión. Sociedad y cultura en la República de Weimar. Valladolid, Universidad de Valladolid, 1996.

Domínguez Hernández, Javier. "Lo romántico y el romanticismo en Schlegel, Hegel y Heine. Un debate de cultura política sobre el arte y su tiempo". Revista de Estudios Sociales, $\mathrm{n}^{\circ}$ 34, 2009, pp. 46-58. 
Eisner, Kurt. La revolución alemana. Madrid, Editorial América, 1920.

---. Sozialismus als Aktion: Ausgewählte Aufsätze und Reden. Frankfurt am Main, Suhrkamp, 1975.

Elias, Norbert. El proceso de la civilizacion. Investigaciones sociogenéticas y psicogenéticas. México DF, Fondo de Cultura Económica, 2010.

Frank, Manfred. El dios venidero: Lecciones sobre la Nueva Mitología. Madrid, Serbal, 1994.

---. Dios en el exilio. Lecciones sobre la nueva mitología. Madrid, Akal, 2004.

Griffin, Roger. Modernismo y fascismo: la sensación de comienzo bajo Mussolini y Hitler. Madrid, Akal, 2010.

Hegel, Georg Wilhelm Friedrich. Lecciones sobre estética. Vol. I. Barcelona, Edicions $62,1989$.

Herf, Jeffrey. El Modernismo reaccionario: tecnología, cultura y política en Weimar y el Tercer Reich. México DF, Fondo de Cultura Económica, 1990.

Hofmannsthal, Hugo Von. Hofmannsthal and the Austrian Idea: Selected Essays and Addresses, 1906-1927. West Lafayette, Purdue University Press, 2011.

Honneth, Axel. “Comunidad. Esbozo de una historia conceptual”. Isegoría, n²0, 1999, pp. 5-15.

Kant, Immanuel. Crítica del Juicio. Madrid, Tecnos, 2007.

Kracauer, Siegfried. The Mass Ornament: Weimar Essays. Cambridge, Harvard University Press, 1995.

Kocka, Jürgen. Historia social y conciencia histórica. Madrid, Marcial Pons, 2002.

Landauer, Gustav. Incitación al socialismo, Buenos Aires, Nervio, 1931.

---. La Revolución. Buenos Aires, Signo Libertario, 1961.

---. Gustav Landauer. Revolution and Other Writings. Ed. Gabriel Kuhn. Pontypool, Merlin Press, 2010.

---. Der Todesprediger. Dresde, Minden, 1903.

---. Zeit und Geist. Kulturkritische Schriften 1890-1919. Eds. R. Kauffeldt, R. y M. Matzigkeist. Regensburg, Boer, 1997.

Löwy, Michael. "The Romantic and the Marxist Critique of Modern Civilization". Theory and Society, $\mathrm{n}^{\circ}$ 16.6, 1987, pp. 891-904.

Mann, Thomas. Consideraciones de un apolítico. Barcelona, Grijalbo, 1978.

Mauthner, Fritz. Contribuciones a una crítica del lenguaje. Barcelona, Herder, 2001.

Mitchell, Allan. Revolution in Bavaria, 1918-1919. The Eisner Regime and the Soviet Republic. New Jersey, Princeton University Press, 1965

Mohler, Armin. Die konservative Revolution in Deutchland, 1918-1932. Stuttgart, Friedrich Vorwerck-Verlag, 1950.

Mosse, George L. "The Mystical Origins of National Socialism” Journal of the History of Ideas, $\mathrm{n}^{\circ} 1.22$, 1961, pp. 81-96.

---. La cultura europea del siglo XIX. Barcelona, Ariel, 1997.

Nietzsche, Friedrich. El origen de la tragedia. Madrid, Espasa, 2007. 
---. Así habló Zaratustra. Buenos Aires, Ediciones Lea, 2012.

Novalis. La cristiandad o Europa. Madrid, Instituto de Estudios Políticos, 1977.

Noever, Peter. The End of Architecture? Documents and Manitestos: Vienna Architecture Conference. Munich, Prestel Verlag, 1992.

Phelan, Anthony, editor. El Dilema de Weimar. Los intelectuales en la República de Weimar. Valencia, Edicions Alfons el Magnanim, 1990.

Renouvin, Pierre. La crisis europea y la Primera Guerra Mundial. Madrid, Akal, 1990.

Rohkrämer, Thomas. "German Cultural Critiscism. The Desire for a Sense of Place and Community". Making a New World: Architecture \& Communities in Interwar Europe. Eds. R. Heynickx y T. Avermaete. Leuven, Leuven University Press, 2012, pp. 31-42.

Spinoza, Baruch. Ética demostrada según el orden geométrico. Madrid, Orbis, 1990.

Taylor, Seth. Left-Wing Nietzscheans. The Politics of German Expressionimsm 19101920. Berlin-New York, Walter de Gruyter, 1990.

Van den Bruck, Moeller. Germans Third Empire. London, G. Allen \& Unwin, 1934.

Washton Long, Rose-Carol, editora. German expressionism: documents from the end of the Wilhelmine Empire to the rise of national socialism. California, University of California Press, 1995.

Weinstein, Joan. The End of Expressionism. Art and the November Revolution in Germany, 1918-19. Chicago, University of Chicago Press, 1990.

Recibido: 5 marzo 2017

Aceptado: 8 enero 2018 